\title{
Plagues, pandemics and epidemics in Irish history prior to Covid-19 (coronavirus): What can we learn? - Corrigendum
}

\author{
Brendan D. Kelly \\ https:/ / doi.org/10.1017/ipm.2020.25
}

In this paper, the sentence 'In Ireland, the flu infected almost 800000 people and more than 20000 died (Foley, 2011).' should read: 'In Ireland, the flu infected almost 800000 people and more than 20000 died (Beiner et al. 2009; Milne, 2018).'

\section{Reference}

Kelly, B. (2020). Plagues, pandemics and epidemics in Irish history prior to COVID-19 (coronavirus): What can we learn? Irish Journal of Psychological Medicine, 1-6. doi: 10.1017/ipm.2020.25 